\section{Commentary: Find first, seek later}

\author{
Kenji Minatoya, MD, $\mathrm{PhD}$
}

Stroke is a devastating complication of cardiovascular surgery. It remains a major issue, especially in open aortic arch surgery, although several adjuncts have been applied. ${ }^{1}$

Ghincea and colleagues ${ }^{2}$ report the early detection of stroke in patient undergoing cardiovascular surgery with hypothermic circulatory arrest. They utilized neurophysiologic intraoperative monitoring (NIOM) consisting of electroencephalography, somatosensory evoked potentials (SSEPs), and motor evoked potentials (MEPs). They conclude that the NIOM has high sensitivity and specificity for the early identification of stroke and high negative predictive value. Each test itself is familiar and SSEPs an MEPs are frequently utilized in operations for thoracoabdominal aortic artery (TAAA) repair to detect spinal cord ischemia (SCI). As an intraoperative monitoring procedure during carotid endarterectomy, SSEPs are used to prevent neurological complications. ${ }^{3}$ The practice of using evoked potentials to detect stroke during cardiac operations was first introduced by a research group at the University of Pennsylvania. ${ }^{4,5}$ They used SSEPs in their series and reported that the ischemic change was related to the removal of the aortic crossclamp and the initiation of cardiopulmonary bypass.

We also have routinely used MEPs during TAAA repair in our practice. Although the MEPs were primarily used for the detection of SCI, abnormality of the signal has been sometimes seen when a patient experiences stroke during the operation. In fact, a report by Liu and colleagues, ${ }^{6}$ describing the utility of SSEPs and MEPs for the prevention of paraplegia, indicated that about $10 \%$ of patients in the series who experienced stroke showed the change of signal. ${ }^{6}$

Ghincea and colleagues ${ }^{2}$ highlight the importance of the early detection of stroke during open aortic arch surgery. The early detection might lead to more sophisticated cerebral protection during aortic arch repair. Postoperative detection of stroke is usually delayed until the recovery

\footnotetext{
From the Department of Cardiovascular Surgery, Graduate School of Medicine, Kyoto University, Kyoto, Japan.

Disclosure: Author has nothing to disclose with regard to commercial support.

Received for publication Feb 27, 2020; revisions received Feb 27, 2020; accepted for publication Feb 28, 2020; available ahead of print March 19, 2020.

Address for reprints: Kenji Minatoya, MD, PhD, Department of Cardiovascular Surgery, Graduate School of Medicine, Kyoto University, 54 Kawaharacho, Shogoin, Sakyo-ku, Kyoto 6068507 Japan (E-mail: minatoya@kuhp.kyoto-u.ac.jp).

J Thorac Cardiovasc Surg 2021;162:1046-7

$0022-5223 / \$ 36.00$

Copyright (c) 2020 by The American Association for Thoracic Surgery

https://doi.org/10.1016/j.jtcvs.2020.02.130
}

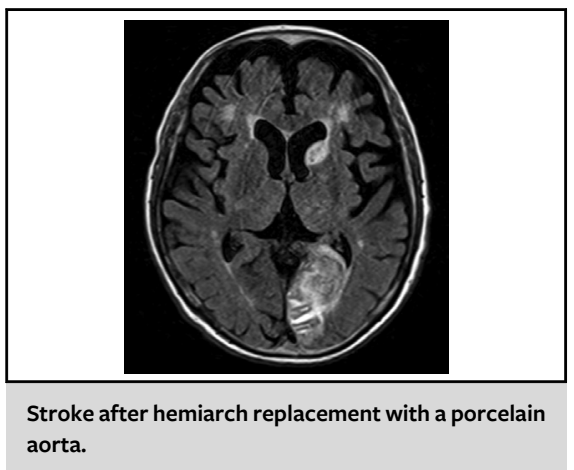

CENTRAL MESSAGE

Safer cerebral protection during aortic arch repair should be sought with NIOM.

from anesthesia-timing that might be too late to correct the cerebral insults. Although detection can be disappointing, it usually allows us to act promptly for the reduction of complications. As the authors mention, earlier postprocedural neurological imaging and possible catheter-based interventions could be performed if we had information of possible stroke earlier (ie, before recovery from anesthesia). We can then re-evaluate the procedure to identify the cause of the stroke. Detection of stroke in real time with NIOM could be a key to remediation of cerebral protection in arch surgery in the future.

MEPs are established monitoring tools to reduce SCI during TAAA repair. A recent multicenter study indicated that the monitoring with MEPs during TAAA repair was not associated with motor deficits at discharge. ${ }^{7}$ This suggests that interventions based on neuromonitoring data do not make any difference. ${ }^{8}$ In fact, when encountered with the change of the signal in the MEPs during TAAA repair, several interventions, including additional reconstruction of segmental arteries and an increase of perfusion pressure, are applied to correct the change. Similar issues could arise in aortic arch repair with neuromonitoring. Yet, the mechanism of SCI is not completely understood and the mechanism of stroke during aortic arch repair is not apparent, either. We should seek safer cerebral protection during aortic arch repair, and this report by Ghincea and colleagues $^{2}$ is a fine reference.

\section{References}

1. Itagaki S, Chikwe J, Sun E, Chu D, Toyoda N, Egorova N. Impact of cerebral perfusion on outcomes of aortic surgery: the Society of Thoracic Surgeons Adult Cardiac Surgery Database analysis. Ann Thorac Surg. 2020;109:428-35. 
2. Ghincea CV, Anderson DA, Ikeno Y, Roda GF, Eldeiry M, Bronsert MR, et al. Utility of neuromonitoring in hypothermic circulatory arrest cases for early detection of stroke: listening through the noise. J Thorac Cardiovasc Surg. 2021;162:1035-45.e5.

3. Nwachuku EL, Balzer JR, Yabes JG, Habeych ME, Crammond D, Thirumala PD. Diagnostic value of somatosensory evoked potential changes during carotid endarterectomy: a systematic review and meta-analysis. JAMA Neurol. 2015;72: 73-80.

4. Cheung AT, Savino JS, Weiss SJ, Patterson T, Richards RM, Gardner TJ, et al. Detection of acute embolic stroke during mitral valve replacement using somatosensory evoked potential monitoring. Anesthesiology. 1995;83:208-10.

5. Stecker MM, Cheung AT, Patterson T, Savino JS, Weiss SJ, Richards RM, et al. Detection of stroke during cardiac operations with somatosensory evoked responses. J Thorac Cardiovasc Surg. 1996;112: 962-72.

6. Liu LY, Callahan B, Peterss S, Dumfarth L, Tranquilli M, Ziganshin BA, et al Neuromonitoring using motor and somatosensory evoked potentials in aortic surgery. J Card Surg. 2016;31:383-9.

7. Yoshitani K, Masui K, Kawaguchi M, Kawamata M, Kakinohana M, Kato S, et al Clinical utility of intraoperative motor-evoked potential monitoring to prevent postoperative spinal cord injury in thoracic and thoracoabdominal aneurysm repair: an audit of the Japanese Association of Spinal Cord Protection in Aortic Surgery Database. Anesth Analg. 2018;126:763-8.

8. Chung J, Ouzounian M, Lindsay T. Motor evoked potential monitoring during thoracoabdominal aortic surgery: useful or not? Anesth Analg. 2018;126: $741-2$.
See Article page 1035.

\section{Commentary: If the news is good, it is better that we know ... if the news is bad, it is better than we know fast}

\author{
Lisa Q. Rong, MD, ${ }^{\mathrm{a}}$ Luca P. Weltert, MD, ${ }^{\mathrm{b}}$ and \\ Mario F. L. Gaudino, MD
}

The risk of stroke in aortic arch (AA) surgery remains a serious concern, despite modern surgical techniques and strategies for cerebral protection. Brain perfusion during AA surgery faces embolic and global ischemic threats, from manipulation and crossclamping of the aorta to malperfusion due to incomplete protective perfusion during the circulatory arrest phase of the operation. Intraoperative diagnosis of stroke can be a challenge, and there are no current standard guidelines for intraoperative neuromonitoring (IONM).

Despite this, data from IONM may allow for early diagnosis of stroke and inform subsequent management of

\footnotetext{
From the a Department of Anesthesiology, Weill Cornell Medicine/New York Presbyterian Hospital, New York, NY; ${ }^{\mathrm{b}}$ Department of Cardiac Surgery, European Hospital, Rome, Italy; and ${ }^{\mathrm{c} D e p a r t m e n t}$ of Cardiothoracic Surgery, Weill Cornell Medicine/New York Presbyterian, New York, NY.

Disclosures: Lisa Q. Rong is supported in part by the Foundation for Anesthesia Research and Education Training Grant (FAER MTRG-CT-08-15-2018-Rong). All other authors have nothing to disclose with regard to commercial support.

Received for publication Feb 11, 2020; accepted for publication Feb 13, 2020; available ahead of print Feb 21, 2020.

Address for reprints: Mario F. L. Gaudino, MD, Department of Cardio-thoracic Surgery, Weill Cornell Medicine, 525 East 68th St, New York, NY 10065 (E-mail: mfg9004@med.cornell.edu).

J Thorac Cardiovasc Surg 2021;162:1047-8

0022-5223/\$36.00

Copyright (c) 2020 by The American Association for Thoracic Surgery

https://doi.org/10.1016/j.jtcvs.2020.02.058
}

Check for updates

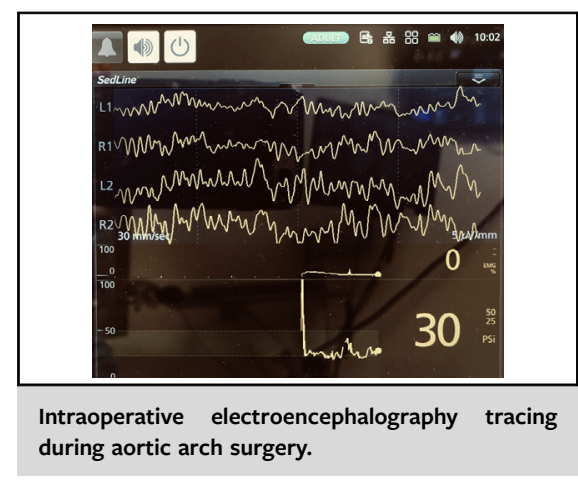

CENTRAL MESSAGE

Intraoperative neuromonitoring can provide early diagnosis and intervention for stroke and provide reassurance that cerebral perfusion is adequate during aortic arch surgery.

the patient. Although the operation may not be aborted, interventions such as optimizing oxygen delivery through increasing mean arterial blood pressure and hematocrit and by decreasing cerebral metabolic rate may decrease sequelae of cerebral hypoperfusion. In addition, in the cases of embolic stroke, early diagnosis allows for the stroke team to be on standby for the possibility of emergent imaging and intervention after the operation is complete. IONM strategies used include electroencephalography (EEG) and evoked potential measurements, transcranial Doppler, and near-infrared spectroscopy (NIRS).

NIRS is most common technique used to diagnose and treat cerebral hypoperfusion in AA surgery. Although 